\title{
GAMBARAN STIGMA PADA PASIEN KANKER PAYUDARA DI RSUD ARIFIN ACHMAD PROVINSI RIAU
}

\author{
Afi NurKhamidah*1, Rani Lisa Indra ${ }^{2}$ Lita $^{3}$ \\ ${ }^{1}$ Mahasiswa PSIK STIKes Hang Tuah Pekanbaru \\ ${ }^{23}$ Dosen PSIK STIKes Hang Tuah PEkanbaru \\ Email Responden: afinurkhamidah17@gmail.com
}

\begin{abstract}
Abstrak
Stigma pada pasien kanker payudara akan berdampak buruk terhadap psikologis sehingga menyebabkan depresi, penurunan harga diri, kecemasan, penolakan dan dikucilkan di lingkungan sekitarnya. Apabila stigma tidak diatasi dapat memperburuk kesehatan khususnya pada kanker payudara. Penelitian ini bertujuan untuk mengetahui gambaran stigma pada pasien kanker payudara di RSUD Arifin Achmad Provinsi Riau. Jenis penelitian ini adalah kuantitatif dengan pendekatan deskritif dengan sampel 53 responden menggunakan consecutive sampling. Analisis yang digunakan adalah univariat dengan menggunakan jenis distribusi frekuensi dan tedensi sentral. Hasil penelitian menunjukkan rerata usia responden 41,4 tahun, mayoritas responden memiliki tingkat pendidikan SMA 25 orang $(47,2 \%)$, bekerja sebagai IRT 50 orang $(94,3 \%)$, terdiagnosa stadium II 25 orang $(47,2)$ dan memiliki stigma 28 orang $(52,8 \%)$. Dapat disimpulkan bahwa sebagian besar pasien kanker payudara di rumah sakit Arifin Achmad Provinsi Riau memiliki stigma. Kepada pasien kanker payudara diharapkan untuk merubah pola fikir yang positif agar tidak memiliki stigma.
\end{abstract}

Kata kunci

: Stigma, Kanker payudara

\begin{abstract}
Stigma in breast cancer patients can affect the negative impact on psychology so that it can be cause depression, decreased self-esteem, anxiety, rejection and isolation in the surrounding environment. If the stigma is not overcome it can worsen the health of breast cancer. The aim of this study was to determine the description of stigma in breast cancer patients in RSUD Arifin Achmad Riau Province. This research was quantitative with descriptive approach with sample of 53 respondents using consecutive sampling. The analysis used was univariate using the type of frequency distribution and central level. The results showed the average age of respondents was 41.4 years, the majority of respondents had a high school education level of 25 peoples (47.2\%), worked as an Hause wife of 50 peoples (94.3\%), diagnosed with stage II 25 peoples (47.2) and had stigma 28 (52.8\%). It can be concluded that most breast cancer patients at Arifin Achmad Hospital in Riau Province have stigma. Breast cancer patients are expected to change positive thinking patterns so they do not have stigma.
\end{abstract}

Keywords : Breast cancer, Stigma

\section{Pendahuluan}

Kanker menurut WHO (World Health Organization) 2018, adalah istilah umum penyakit yang dapat mempengaruhi bagian tubuh. Istilah lain yang digunakan adalah tumor 
ganas dan neoplasma. Dimana terjadi pembelahan sel yang tidak terkendali dari suatu bagian tubuh, kemudian dapat menyerang bagian tubuh yang bersebelahan dan dapat menyebar ke organ lainnya.

Menurut WHO (World Health Organization) 2018, pada tahun 2015 ada 8,8 juta orang meninggal akibat kanker. Angka tertinggi disebabkan oleh kanker paru sebanyak 1,69 juta dan kanker payudara berada pada urutan ke 5 sebanyak 571 ribu. Berdasarkan data Global Burden of Cancer (GLOBOCAN) dan International Agency for Reseacrh on Cancer (IARC) tahun 2012, jumlah kanker payudara di dunia mencapai 1,67 juta penderita dan kematian akibat kanker diseluruh dunia mencapai 8,2 juta orang (Ferlay et al., 2015).

Sementara pada tahun 2013 penderita kanker payudara semua usia secara nasional di Indonesia yaitu sekitar $1,4 \%$ atau diperkirakan 347.792 orang. Jumlah penderita kanker payudara di Provinsi Riau yaitu 894 orang (Kemenkes, 2015). Data rekam medis RSUD Arifin Ahmad pada tanggal 1 Januari 2017 sampai tanggal 14 Febuari 2018, pasien penderita kanker payudara berjumlah 2.810 orang dengan indeks kematian sebanyak 59 orang. Pada usia 45-65 tahun jumlah tertinggi penderita kanker payudara sebanyak 1.625 orang dengan indeks kematian sebanyak 38 orang.
Penderita kanker payudara biasanya mengalami perubahan bentuk dan ukuran pada payudara ditandai kerutan pada kulit payudara sehingga menyerupai kulit jeruk, adanya cairan tidak normal berupa nanah, darah, dan cairan encer yang keluar dari puting susu (Suryaningsih dan Sukaca dalam Dewi dan Hendrati, 2015).

Stigma menurut Kamus Besar Bahasa Indonesia (KBBI) tahun 2014, yaitu ciri negatif yang menempel pada pribadi seseorang karena pengaruh lingkungannya. Dari hasil penelitian tersebut dapat dipahami bahwa mereka memberi stigma negatif pada pasien kanker. Seseorang memberi pelebelan dikarenakan individu tersebut dianggap ternoda, mempunyai watak yang tercela, sakit mental, cacat fisik, dan penyakit tertentu (Goffman dalam Shintadewi dan Sumartias, 2017).

Stigma secara menyeluruh tentang kanker bahwa stigma membawa dampak psikologis ditandai penurunan harga diri, kecemasan dan depresi (Cataldo dan Brodsky, 2012). Levi-minzi \& Surrat dalam Rifai (2016) mengatakan dampak yang ditimbulkan dari stigma dapat mempengaruhi kualitas hidup serta kondisi kesehatan mereka yang distigmatisasi. Lai Hong dan Chee dalam Sarwono (2013) juga mengatakan dampak langsung stigma adalah rasa rendah diri, malu dengan penyakitnya, takut akan penolakan 
sosial, takut kesulitan mendapatkan pekerjaan. Pemberian Stigma juga dapat mengganggu sumber daya manusia, kesempatan hidup sehat, bahkan penganiyaan berupa diskriminasi (Shintadewi dan Sumartias, 2017).

Stigma yang mengenai kanker bahwa penyakit kanker dapat menular, tidak dapat disembuhkan dan ada juga yang mengatakan sebagai kutukan. Kondisi seperti ini membuat kondisi mental penderita kanker menjadi buruk dan frustasi. Sedangkan kondisi kejiwaannya banyak penderita kanker merasa putus asa dan tidak berdaya, sehingga penderita tidak mau mencari pengobatan tentang kanker dan pasrah dengan kondisinya (Humasfik, 2017).

Stigma yang terkait dengan kanker payudara menimbulkan sikap negative, mereka merasa menghindar dari orang lain. Salah satu tindakan dari efek ini karena adanya perubahan citra tubuh bisa di dapat dari akibat mastektomi. Mastektomi ini salah satu tindakan dari kanker payudara. Mereka yang melakukan mastektomi pada pasien kanker payudara belum tentu menerima dari tindakan tersebut, karena akan mengalami perubahan citra tubuh, gangguan psikologis, disfungsi seksual, depresi, kualitas tidur yang buruk, tekanan ekonomi, dukungan sosial yang buruk, dan penurunan kualitas hidup (Wang, 2017).
Suwankhong dalam Wang (2017) menjelaskan untuk pengobatan kanker payudara khususnya kemoterapi, hampir semua pasien kanker payudara mengalami efek dari kemoterapi yang dimana pasien menangggung berbagai efek yang merugikan dari perawatan mereka, termasuk mual, muntah, kelelahan, rambut rontok, kurang nafsu makan, dan dapat menyebabkan ketidak percayaan diri sehingga persepsi mereka dari diri sendiri akan merasa berbeda, bahkan terasingkan. Sebagian besar pasien kanker payudara merasa malu karena perubahan citra tubuh dan mencari cara untuk menyembunyikan bagian tubuh mereka yang tidak sempurna, sebab payudara merupakan simbol identitas kewanitaan.

Berdasarkan survei pendahuluan yang dilakukan peneliti kepada 4 responden yang menjalani kemoterapi, 1 orang mengatakan bahwa orang yang menderita kanker payudara merasa dikucilkan, 2 orang menyatakan kanker sebagai kutukan, merasa dijauhi dan depresi. 1 orang juga menyatakan pandangan masyarakat baik dan saling mendukung.

Berdasarkan latar belakang tersebut, peneliti ingin mengetahui gambaran stigma kanker payudara di RSUD Arifin Achmad Provinsi Riau.

\section{Metode Penelitian}

Penelitian ini merupakan penelitian yang digunakan kuantitatif 
dengan desain deskritif. Dengan 53 responden menggunakan teknik consecutive sampling dengan cara membatasi waktu. Alat pengumpulan data menggunakan kuesioner. Peneliti melakukan Uji Etik di FK UNRI. Analisa yang digunakan adalah analisa univariat.

\section{Hasil}

Karakteristik responden dilihat dari pendidikan responden, menunjukkan bahwa mayoritas pendidikan SMA sebanyak 25 orang (47,2\%), pendidikan SMP sebanyak 14 orang $(26,4 \%)$, pendidikan SD sebanyak 14 orang $(26,4 \%)$.

Tabel 1. Karakteristik Responden Pendidikan

\begin{tabular}{llll}
\cline { 3 - 4 } No & Pendidikan & Jumlah & $\%$ \\
\hline 1. & SD & 14 & 26,4 \\
\hline 2. & SMP & 14 & 26,4 \\
\hline 3. & SMA & 25 & 47,2 \\
\hline \multicolumn{2}{l}{ Total } & 53 & 100 \\
\hline
\end{tabular}

Tabel 2. Ditrubusi Responden Pekerjaan

\begin{tabular}{llll}
\cline { 3 - 4 } No & Pekerjaan & Jumlah & $\%$ \\
\hline 1. & IRT & 50 & 94,3 \\
\hline 2. & Pedagang & 3 & 5,7 \\
\hline & Total & 53 & 100 \\
\hline
\end{tabular}

Berdasarkan tabel 2 dapat dilihat bahwa yang pekerjaan responden sebagai IRT sebanyak 50 orang (94,3\%), sedangkan yang bekerja sebagai pedagang terdapat $3(5,7 \%)$.

Tabel 3. Ditrubusi Responden Riwayat Pengobatan

\begin{tabular}{llll}
\hline No & Riwayat & Jumlah & $\%$ \\
& Pengobatan & & \\
\hline 1. & Operasi & 23 & 43,4 \\
\hline 2. & Kemoterapi & 7 & 13,2 \\
\hline 3. & $\begin{array}{l}\text { Kemoterapi } \\
\text { dan }\end{array}$ & 23 & 43,4 \\
& $\begin{array}{l}\text { Operasi } \\
\text { Total }\end{array}$ & 53 & 100 \\
\hline
\end{tabular}

Berdasarkan tabel 3 dapat dilihat bahwa responden yang menjalani operasi sebanyak 23 orang $(43,4 \%)$, yang menjalani kemoterapi sebanyak 7 orang (13,2\%), sedangkan menjalani operasi dan kemoterapi sebanyak 23 orang $(43,3 \%)$.

Tabel 4. Ditrubusi Responden Stadium

\begin{tabular}{llcc}
\cline { 3 - 4 } No & Stadium & Jumlah & $\%$ \\
\hline 1. & Stadium 1 & 1 & 1,9 \\
\hline 2. & Stadium 2 & 25 & 47,2 \\
\hline 3. & Stadium 3 & 19 & 35,8 \\
\hline 4. & Stadium 4 & 8 & 15,1 \\
\hline & Total & 53 & 100 \\
\hline
\end{tabular}

Berdasarkan tabel 4 dapat dilihat bahwa responden mayoritas mengalami stadium II yaitu 25 
(47,2\%). Sedangkan pada stadium III sebanyak 19 (35,8\%) tidak pernah melakukan pemeriksaan payudara sendiri.

Tabel 5. Ditrubusi Responden Stigma

\begin{tabular}{llcc}
\hline No & Stigma & Jumlah & $\%$ \\
\hline 1. & Ada stigma & 28 & 52,8 \\
\hline 2. & $\begin{array}{l}\text { Tidak ada } \\
\text { stigma }\end{array}$ & 25 & 47,2 \\
\cline { 1 - 2 } & Total & 53 & 100 \\
\hline
\end{tabular}

Berdasarkan tabel 5 dapat dilihat bahwa dari 53 responden yang memiliki stigma sebanyak 28 $(52,8 \%)$.

\section{Pembahasan}

\section{Pendidikan}

Berdasarkan hasil penelitian yang dilakukan di RSUD Arifin Achmad Provinsi Riau hasil analisis menunjukan bahwa sebagian besar pendidikan terakhir responden adalah Sekolah Menengah Atas yaitu 25 $(47,2 \%)$. Hal ini sesuai dengan teori Handayani dalam Jannah (2017), yang mengatakan bahwa tingkat pendidikan menunjukkan kemampuan dalam berfikir dan yang cukup, semakin dalam mengambil keputusan yang sesuai dan menurut individu benar serta realita sesuai dengan pengalaman pengetahuan yang didapat.

\section{Pekerjaan}

Berdasarkan penelitian di Rumah Sakit Arifin Achmad Provinsi Riau didapatkan bahwa mayoritas status pekerjaan pasien kanker payudara adalah, yaitu 52 (98,1\%). Hasil penelitian ini didukung oleh Dyanna, Yulia, dan Herlina (2015) yang menyatakan bahwa mayoritas pasien kanker payudara di Rumah Sakit Umum Daerah Arifin Achmad provinsi Riau adalah IRT dikarenakan IRT rata-rata menggunakan alat kontrasepsi seperti pil atau suntik $\mathrm{Kb}$ dalam kurun wakru relatif lama. Pemakaian alat kontrasepsi jika lebih dari 8-10 tahun akan mengkibtkan peningkatan risiko terjadinya kanker payudara (Taris \& Suyatno, 2010).

\section{Stadium}

Berdasarkan penelitian yang dilakukan di Rumah Sakit Umum Daerah Arifin Achmad Provinsi Riau didapatkan bahwa mayoritas pasien kanker payudara rata-rata berada pada stadium 2 sebanyak 24 (45,3\%). Hal ini sejalan dengan penelitian yang dilakukan oleh Setyaningsih 
dalam Ningsih, Karim dan Sabrina (2015), yang menyebutkan bahwa jumlah terbanyak ada di stadium 2 yaitu 50\%, sedangkan stadium 3 sebesar 42\%. Stadium kanker biasaya diketahui mulai dari stadium 2, karena pada tahap ini benjolan mulai muncul dan berubah menjadi besar. Ukurannya diantara 2 hingga 5 $\mathrm{cm}$, tingkat penyebaran juga sudah sampai di area ketiak.

Penelitian yang dilakukan Smith et al (2008) menyatakan bahwa keterlambatan penderita untuk memulai deteksi dini mereka mengalami kecemasan serta ketakutan untuk menjalani operasi. Penelitian ini sejalan dengan hasil studi Van den Beuken van (2008) yaitu hambatan yang dirasakan penderita saat diketahui adanya kanker payudara untuk memulai pengobatannya terdapat reaksi tidak percaya nya penyakit yang dialaminya. Selama individu tidak percaya atas penyakit yang telah diderita, maka stadium yang dialaminya terus berkembang. Selain alasan tersebut, individu takut untuk pergi ke rumah sakit dan tidak memiliki biaya.

\section{Stigma}

Berdasarkan penelitian yang dilakukan di Rumah Sakit Umum Daerah Arifin Achmad Provinsi Riau didapatkan bahwa mayoritas pasien kanker payudara memiliki stigma sebanyak 29 orang $(54,7 \%)$. Hasil penelitian ini didukung oleh penelitian yang dilakukan oleh Anggreni, Yohanes (2017) yang menyatakan bahwa stigma dapat menekan konsep diri individu sehingga munculnya rasa ketidakpercayaan terhadap diri sendiri yang mengakibatkan individu tersebut tidak mampu berinteraksi dengan lingkungan sekitarnya.

Menurut Major dan O'brein (2005) dalam penelitiannya menyebutkan stigma menjadi ancaman terhadap identias yang dimiliki individu sehingga dapat menimbulkan stres dan berpengaruh terhadap dirinya sendiri. Dampak negatif dari stigma tersebut dapat menimbulkan ketidakinginan pada pasien tersebut untuk melakukan pengobatan. Penelitian dalam Cho et al (2013), menyebutkan bahwa stigma pada pasien kanker payudara memiliki tingkat depresi 
lebih tinggi dibandingkan penyakit kanker lainnya. Depresi menyebabkan kualitas tidur menurun, kurangnya semngat untuk sembuh serta keinginan bertahann hidup berkurang.

Hasil penelitian Chris dalam Guntari (2016), mengatakan bahwa penderita kanker payudara menilai diri nya secara negatif dan cendrung tidak puas dengan penampilannya. Hal ini menyebabkan individu menampilkan kesan negatif seperti rasa malu dan rendah diri terhadap orang lain karena keadaan fisik yang tidak sempurna dan tidak sesuai dengan harapan.

Berdasarkan hasil penelitian mayoritas responden merasa sebentar lagi akan meninggal dunia, hal ini sejalan dengan penelitian Hartati dalam Sudana, Chisnawari dan Anastasia (2016), yang menyatakan bahwa saat individu mengenal dan mengetahui dirinya terkena kanker payudara individu tersebut merasa cemas dan khawatir kematian akan datang serta individu merasa membebankan orang lain. Mayoritas responden merasa seperti orang cacat terhadap penyakit yang diderita dan pernyataan responden berfikir tidak normal saat menderita penyakit kanker payudara, hal ini sejalan dengan teori menurut Herawati dalam Ningsih, Karim dan Sabrina, (2015) yang menyatakan saat individu mengetahui kelainan pada payudaranya individu merasa terpukul, sehingga individu merasa malu dengan bentuk payudaranya, merasa tidak menarik lagi, depresi dan putus asa.

\section{Kesimpulan}

Mayoritas responden memiliki tingkat pendidikan Sekolah Menengah Atas, bekerja sebagai ibu rumah tangga (IRT), terdiagnosa stadium 2, dan memiliki stigma.

\section{Ucapan Terima Kasih}

Terima kasih kepada pihak Rumah sakit Umum Daerah Arifin Achmad Provinsi Riau yang telah memfasilitasi terhadap penyelesain dalam penelitian ini.

\section{Referensi}

Anggreni, N. W. Y., \& Herdiyanto, Y. K. (2017). Pengaruh stigma terhadap self esteem pada remaja perempuan yang 
mengikuti ekstrakulikuler tari bali di sman 2 denpasar. Jurnal Psikologi Udayana, 4 (1), 208221.

Cataldo, J. K., \& Brodsky, J. L. (2013). Lung cancer stigma, anxiety, depression and symptom severity. Oncology, 85(1), 33-40.

Cho, J., Choi, E. K., Kim, S. Y., Shin, D. W., Cho, B. L., Kim, C. H., ... \& Park, J. H. (2013). Association between cancer stigma and depression among cancer survivors: a nationwide survey in Korea. Psycho-

Oncology, 22(10), 2372-2378.

Dewi, G. A. T., \& Hendrati, L. Y. (2015). Analisis risiko kanker payudara berdasar riwayat pemakaian kontrasepsi hormonal dan usia menarche. Jurnal Berkala Epidemiologi, 3 (1), 12-23.

Dyanna, L., Yulia, I. D., \& Herlina. Hubungan dukungan keluarga terhadap mekanisme koping pasien post operasi mastektomi. JOM, 2 (1), 558568.
Ferley, J., Soerjomataram, I., Dikshit, R., Eser,. S., Mathers, C., Rebelo, M., Bray, F. (2015). Cancer incidence and mortality worldwid: Sources, methos and major patterns in GLOBOCAN 2012. International Journal of Cancer, 136: 359-386. DOI; 10.1002/itj. 29210

Guntari, S., Agung, G., \& Suariyani, NPL (2016). Gambaran fisik dan psikologis penderita kanker payudara post mastektomi di Rsup Sanglah Denpasar Tahun 2014. Arsip kesehatan masyarakat, 3 (1), 24-35

http://kbbi.web.id/stigma Diakses pada tanggal 28 April 2018, pukul 21.08 WIB

Humasfik, (2017). Sosialisasi pencegahan dan pengobatan kanker untuk melawan stigma buruk dimasyarakat. Diperoleh dari http://uiupdate.ui.ac.id/article/s osialisasi-pencegahan-danpengobatan-kanker-untukmelawan-stigma-buruk-dimasyarakat 
Kementrian kesehatan RI. Info datin: Stop kanker. Jakarta: Pusat data dan informasi kementrian kesehatan RI

Link, Bruce and Phelan. (2010). A Hand Book For The Study Of Mental Disorder: Chambridge: Chambridge University Press

Major, B., \& O'brien, L. T. (2005).

The social psychology of stigma. Annu. Rev. Psychol., 56, 393-421.

Ningsih, S. F., Karim, D., \& Sabrian, F. (2015). Efektivitas Terapi Emotional Freedom Technique (Eft) Terhadap Kecemasan Pasien Kanker Payudara Stadium II Dan III. Jurnal Online Mahasiswa Program Studi Ilmu Keperawatan Universitas Riau, 2(2), 15011509.

Nuryati, E., \& Sari, R. (2015). Faktor determinan kanker payudara. Jurnal Ilmiah

Nyblade, L., Stockton, M., Travasso, S., \& Krishnan, S. (2017). A qualitative exploration of cervical and breast cancer stigma in Karnataka,
India. BMC women's health, 17(1), 58.

Qomariah, S., Sartika. S., \& Juwita S., (2018). Deteksi Dini Kanker Payudara Di Kelurahan Limbungan Kecamatan Rumbai Pesisir. Jurnal Pengabdian Masyarakat Multidisiplin, 1(1), 57-56

Rifai, A. (2016). Brief Psychoeducation Intervention Against Hiv/Aids Related Stigma Among House Wifes Lived In Coffee Plantation Area. Jurnal Keperawatan Muhammadiyah, 1(2).

Shintadewi, E. A., \& Sumartias, S. (2017). Promosi kesehatan hivaids dan stigma terhadap pengguna narkoba suntik (penasun) di kabupaten sumedang. Sosiohumaniora, 19 (2).

Smeltzer, Suzanne (2001).

Keperawatan Medikal Bedah

Brunner \& Suddarth Edisi 8

Volume 2. Jakarta: Penerbit

Buku Kedokteran EGC

Smith, E. R., Adams, S. A., Das, I.

P., Bottai, M., Fulton, J., \& Hebert, J. R. (2008). Breast 


cancer survival among
economically disadvantaged
women: the influences of
delayed diagnosis and
treatment on mortality. Cancer
Epidemiology and Prevention
Biomarkers, 17(10), 2882-
2890.

Sudana, I. K., Chrisnawati, C., \& Maratning, A. (2016). Gambaran harga diri pada pasien kanker payudara yang menjalani kemotrapi DI RSUD ULIN BANJARMASIN. Jurnal Keperawatan Suaka Insan, 1(1), 1-6.

The word healt organization. Cancer (2018). www.who .int/newsroom/fact-sheets/detail/cancer.

Wang, Q. X., Bai, Y., Lu, G. F., \& Zhang, C. Y. (2017). Perceived health-related stigma among patients with breast cancer. Chinese Nursing

Research.

Widiawaty, N. (2012). Hubungan Tingkat Pendidikan Formal dan Tingkat Pengetahuan Wanita Tentang Kanker Payudara dengan Kejadian Kanker Payudara di Borokulon Banyuurip Purworejo.Jurnal Komunikasi Kesehatan (edisi 3), 2(02).

Van den Beuken-van Everdingen, M. H., Peters, M. L., de Rijke, J. M., Schouten, H. C., van Kleef, M., \& Patijn, J. (2008). Concerns of former breast cancer patients about disease recurrence: a validation and prevalence study. Psycho-

Oncology: Journal of the Psychological, Social and Behavioral Dimensions of Cancer, 17(11), 1137-1145 